\title{
Design and Evaluation Non-Polarized Antireflection Coatings at High incidence angles
}

\author{
Alaa Nazar abdAlgaffar*, Sara Aamer Salman* \\ *Department of Physics, College of Science for Women, University of Baghdad, Iraq
}

\begin{abstract}
This study demonstrated designs of non polarizing AR coatings at high incidence angles for visible region. Results appear new design stacks of non- polarizing AR coatings with optimal specifications such as low reflectance for the performance of both S-and P-polarizations and limit the separation of the two planes of polarization whenever the angles of incidence increased.
\end{abstract}

\section{Introduction}

Optical coatings are used to change the spectral intensity distribution or the state of polarization of the electromagnetic radiation incident on it for satisfying performance specifications $[1,2,3]$. Optical interference filter is the preferred type of optical coatings, which use the phenomenon of interference waves. Such filters consists of a number of thin films de-posited on substrate, and have the property of being able to enhance transmission or reflection properties within an optical system, in order to get common types of interference coatings such as anti reflection coatings.[4,5,6,7].

Antireflection coatings were the principal topic of much of the early work in thin-film optics. also they have had the greatest impact on technical optics, and even today, in sheer volume of production, they still exceed all other types of coating. Antireflection coatings are simply required for the reduction of surface reflection to increase the transmittance [8].

Antireflection coatings can range from a single layer having virtually zero reflectance at just one wavelength, to a multilayer system of many layers having virtually zero reflectance over a wide spectral range. as a result, it can classified according to optical performance into v-type, Dual wavelength type, and Broadband antireflection coating[9].

AR coatings have been widely used in applications that include glass like lenses, eyeglasses, lasers, mirrors, IR diodes, architectural and automotive glass and displays such as cathode ray tubes, plasma, liquid crystal and flat panel displays. In addition, for optical and electro-optical systems in telecommunications, medicine, military products and consumer products[10].

\section{Problem Definition}

At oblique incidence of light, the optical performance of anti-reflection coatings, splits into two modes of wave, which they are $\mathrm{P}$ - and $\mathrm{S}$ polarization(consequence of polarization phenomenon) [8]. This is because the effective indices of refraction for the surrounding media and coating layer materials have a different function to the angle of incidence for each polarization plane thus the reflectance of S- and P-polarized light tends to be different .[11].

The knowledge indicates that the increase of incident angle expands the separation of reflection performance for both S- and P-polarized wave [8]. also leads to increase the reflectance with shifting toward shorter wavelengths this shifting may be as result of varying the optical thickness of layer due to the oblique incidence of plane electromagnetic wave[6,11].So it is challenge to achieve non-polarizing anti reflection coatings that have the same low reflection performance without seperation for both S- and P-polarization at high incident angles.

In this paper, we design and submitted several different construction design stacks of non polarizing AR coatings that consist of two or more dielectric layers for visible region $(300-800 \mathrm{~nm}$ ) at high incident angels with offering promising coating materials system that used in design three types of antireflection coatings in visible region.

\section{Theoretical Background}

As mentioned coatings at high angles of incidence present special problems. Where the optical performance includes an obvious variation in properties with angle of incidence for the two modes of polarization . Based on that the refraction indices should be modified corresponding to the two modes of wave, S-polarization and P-polarization which are demonstrated as following $[8,12]$ :

$\mathbf{n}_{\mathbf{p}}=\mathrm{n} / \cos \theta$ the effective refractive index for $\mathrm{p}$-polarization $\mathbf{n}_{\mathbf{S}}=\mathrm{n}^{*} \cos \theta$ the effective refractive index for s-polarization 
This study depends Characteristics Matrix to determine the spectral transmittance profile for multilayer structures on a substrate. Characteristics matrix are assembly of q thin film layers, simply characteristic matrix is product the individual matrices for the individual layers of assembly taken in the correct order, given by $[8,13,14]$ :

$\left[\begin{array}{l}\mathrm{C} \\ \mathrm{B}\end{array}\right]=\left(\prod_{\mathrm{r}=1}^{\mathrm{q}}\left[\begin{array}{cc}\cos \delta_{\mathrm{r}} & \left(\mathrm{i} \sin \delta_{\mathrm{r}}\right) / \mathrm{n}_{\mathrm{r}} \\ \mathrm{in}_{\mathrm{r}} \sin \delta_{\mathrm{r}} & \cos \delta_{\mathrm{r}}\end{array}\right]\right)\left[\begin{array}{c}1 \\ \mathrm{n}_{\mathrm{s}}\end{array}\right]$.

$n r, \mathrm{dr}$ are refractive index and physical thickness of layer $\mathrm{q}$ is the number of layers next to substrate $n_{s}$ is the refractive index of the substrate. $\delta \mathrm{r}=2 \pi n_{r} \mathrm{~d}_{\mathrm{r}} \cos \theta / \lambda$

$(\theta)$ is an angle of incident light

$\left[\begin{array}{l}B \\ C\end{array}\right]$ is defined as the characteristic matrix of the assembly.

The expression of reflecttance for whole multilayer system is given as following:

$\eta_{0}$ effective index of incident medium

$$
R=\left(\frac{\eta_{\mathrm{o}} B-C}{\eta_{\mathrm{o}} B+C}\right)\left(\frac{\eta_{\mathrm{o}} B-C}{\eta_{\mathrm{o}} B+C}\right) *
$$

\section{Results And Discussion}

In this work, we synthesize new construction stacks of non-polarized anti reflection coatings at different high incident angles in visible region (300-800 $\mathrm{nm}$ ) atdesign wavelength $\lambda_{0}=550 \mathrm{~nm}$. Advanced system of dielectric coating layers with adopting glass as substrate is used to get optimal performance of non-polarized anti-reflection coatings. The optimal performance includes reducing the reflection and get intersection between the optical performance curve of the two planes of polarization. Table (1) shows dielectric coating materials systems.

Table (1) dielectric coating materials deposited on glass as substrate

\begin{tabular}{|c|c|c|}
\hline Configuration & Materials & Refractive index \\
\hline One minimum reflectance (V-coat) & $\mathrm{SiO}$ & 1.86 \\
\cline { 2 - 3 } & $\mathrm{SnZ}$ & 2.3 \\
\hline Two minimum points of reflectance & $\mathrm{MgF} 2$ & 1.38 \\
\cline { 2 - 3 } (W-coat) & $\mathrm{Al} 2 \mathrm{O} 3$ & 1.62 \\
\cline { 2 - 3 } & $\mathrm{MgF} 2$ & 1.38 \\
\hline \multirow{3}{*}{ Broadband coat } & $\mathrm{MgF} 2$ & 1.38 \\
\cline { 2 - 3 } & $\mathrm{ZnS}$ & 2.3 \\
\cline { 2 - 3 } & $\mathrm{MgO}$ & 1.7 \\
\hline
\end{tabular}

\section{1 non-polarized V-coat type}

In this section several construction design stacks of non-polarized V- type ARat high angles incidence are presented in figures $(1 \mathrm{a}, 1 \mathrm{~b})$. the optical performance of such designs involving low reflection at specific wavelength (design wavelength $550 \mathrm{~nm}$ ). In these designs we achieved a good progress in design of nonpolarized v-coat antireflection where we got optical performance forS and P-polarization has zero reflection at wavelength design with high similarity in for $\mathrm{S}$ and P-polarization.

Figure(1.a) demonstrates the performance and the construction design stack of non-polarized v-coat anti reflection at $\theta_{\mathrm{o}}=45^{\circ}$ as it is clear that there is intersection between the two plane of polarization with low reflection at wavelength design. 


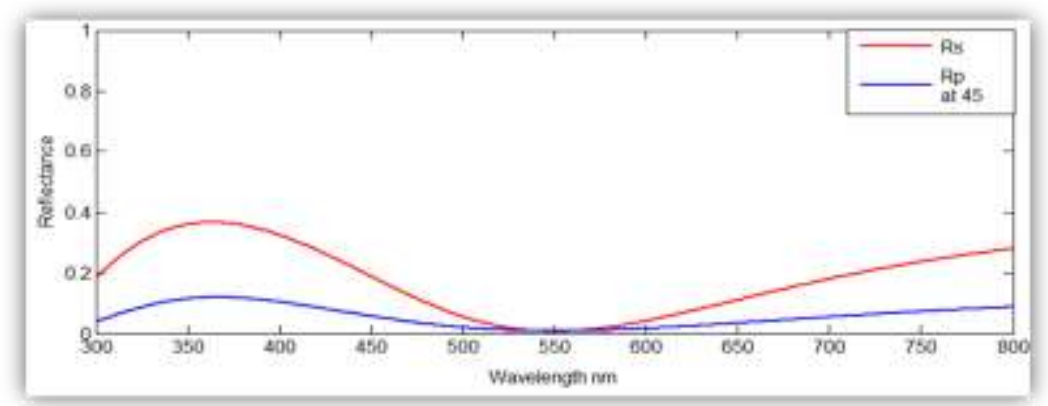

Figure (1.a) optical performance ofnon polarizationARC, $\theta_{0}=45^{\circ}$ with construction design stack:Air $|1.0812 \mathrm{~L}|$ $1.0509 \mathrm{H}$ |Glass

At figure (1.b) we achieved another progress when got a very good performance of of non-polarized vcoat anti reflection at higher incidence angle at $\theta_{\mathrm{o}}=55^{\circ}$

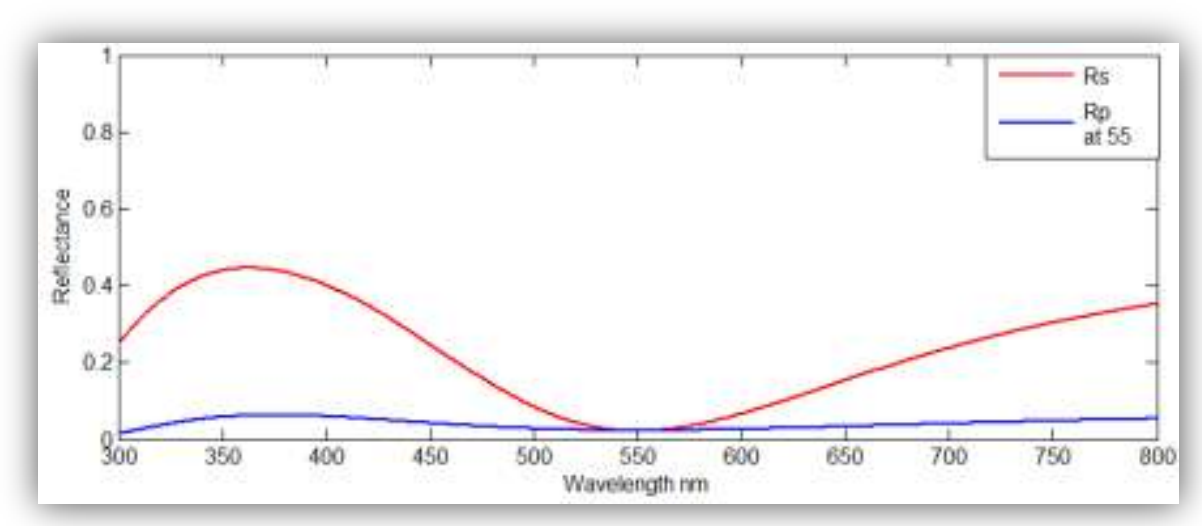

Figure (1.b) optical performance ofnon polarizationARC, $\theta_{\mathrm{o}}=55^{\circ}$ with construction design stack: Air $\mid 1.1138 \mathrm{~L}$ | $1.0702 \mathrm{H}$ |Glass

As it's known the increase of incident angle leads to increase reflectance with shifting toward shorter wavelengths, but it's clear that we could to overcome this problem when we got designs without shifting with still getting low reflection at wavelength design.

\section{2 non-polarized $W$-coat type}

In this section several construction design stacks of non-polarized Dual band antireflection at high angles of incidence are presented in figures $(2 \mathrm{a}, 2 \mathrm{~b}, 2 \mathrm{c})$.

This coating is designed to provide low reflection at two different wavelength.

Successfully we obtained designs with zero reflectance at two different wavelength at high angle of incidence when $\theta_{\mathrm{o}}=45^{\circ}$ for both $\mathrm{S}$ and $\mathrm{P}$ modes of polarization as it is shown in figure (2.a).

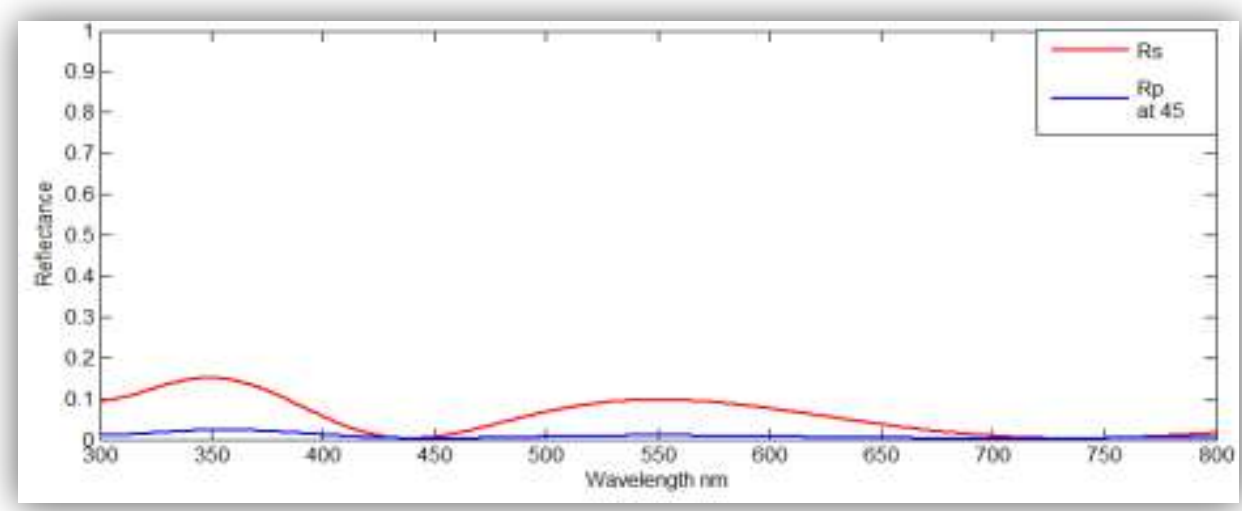

Figure (2.a) optical performance of non polarization ARC, $\theta_{\mathrm{o}}=45^{\circ}$ with construction design stack : Air $\mid 1.1645$ $\mathrm{L}|1.1115(2 \mathrm{H})| 1.1645 \mathrm{~L}$ |Glass 
Figures (2.b,2.c) demonstrate the optical performancewith construction design stack of non-polarized Dual band antireflection at higher incidence angles when $\theta_{0}=55^{\circ}, 60^{\circ}$. As its obvious that the increase of incident angle increases the reflection. In spite of that we still achieved a very good reducing in the reflection of glass surface with completely intersect between $\mathrm{S}$ and $\mathrm{P}$ modes of polarization at two different wavelength.

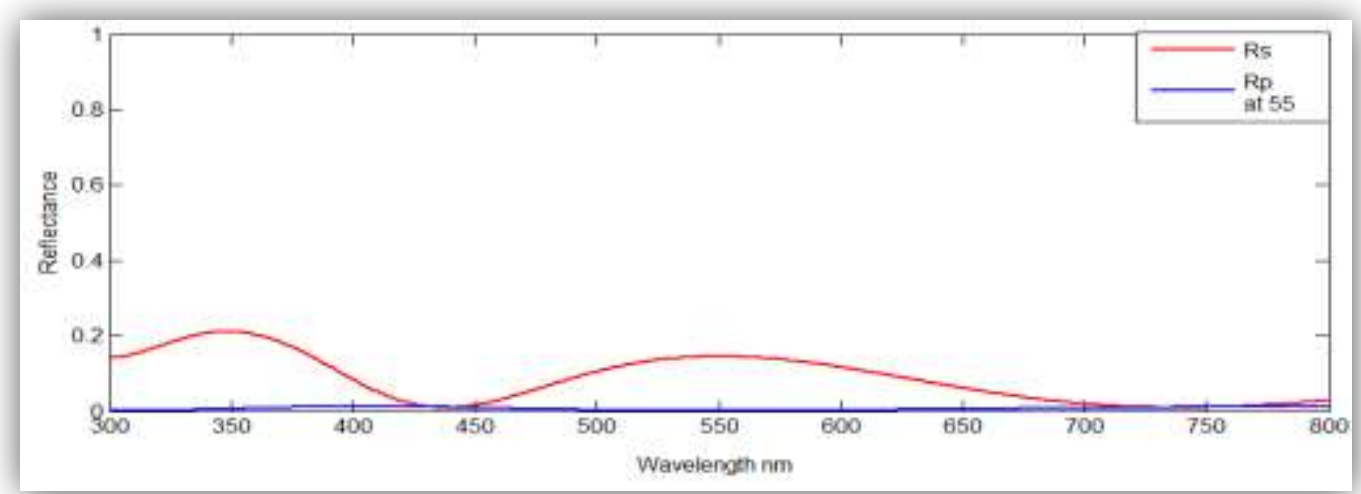

Figure (2.b) optical performance of non polarization ARC, $\theta_{\mathrm{o}}=55^{\circ}$ with construction design stack : Air $\mid 1.2426$ $\mathrm{L}|1.1591(2 \mathrm{H})| 1.2426 \mathrm{~L}$ |Glass

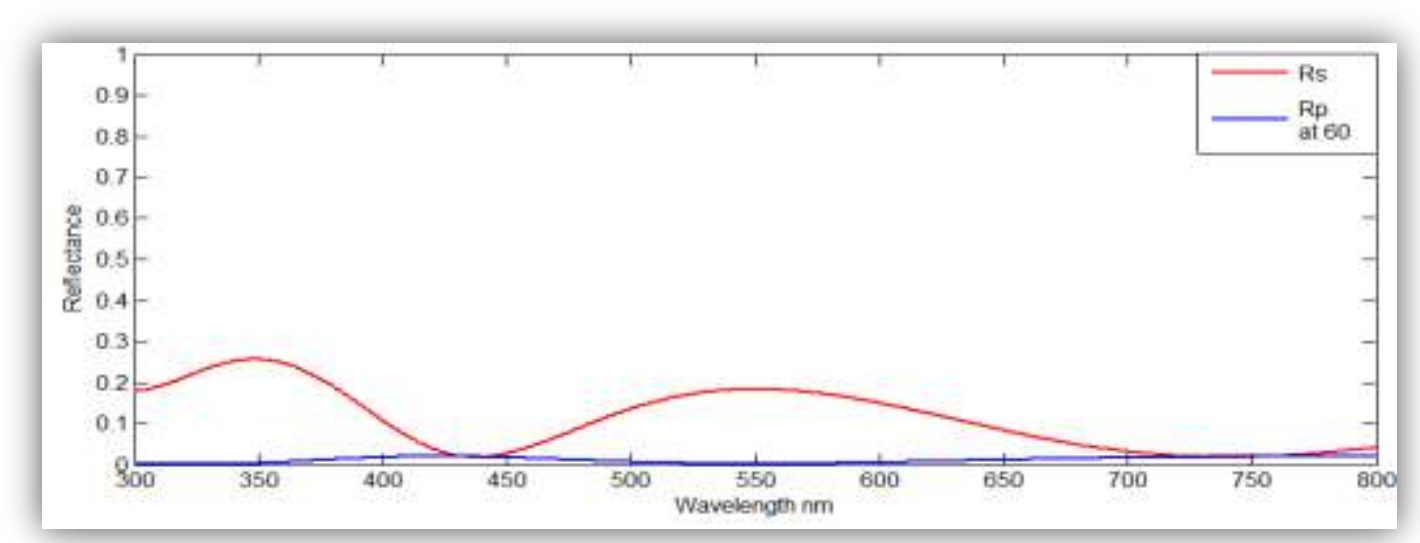

Figure (2.c) optical performance of non polarization ARC, $\theta_{\mathrm{o}}=60^{\circ}$ with construction design stack :Air|1.2844 $\mathrm{L}|1.1833(2 \mathrm{H})| 1.2844 \mathrm{~L}$ |Glass

\section{3 non-polarized Broadband}

In this section designs of non-polarized broadband antireflection are presented in figures (3.a,3.b,3.c,3.d). The optical performance of broadband antireflection provides low reflectance along range of wavelengths. We succeeded in design non-polarized broadband antireflection involving advanced optical performance at high incident angles. Where we got low reflection along wide range of wavelength for both $\mathrm{S}$ and P-polarized waves within range $(450-800 \mathrm{~nm})$ when $\theta_{\mathrm{o}}=45^{\circ}$. such design is shown in figure (3.a) with construction stack.

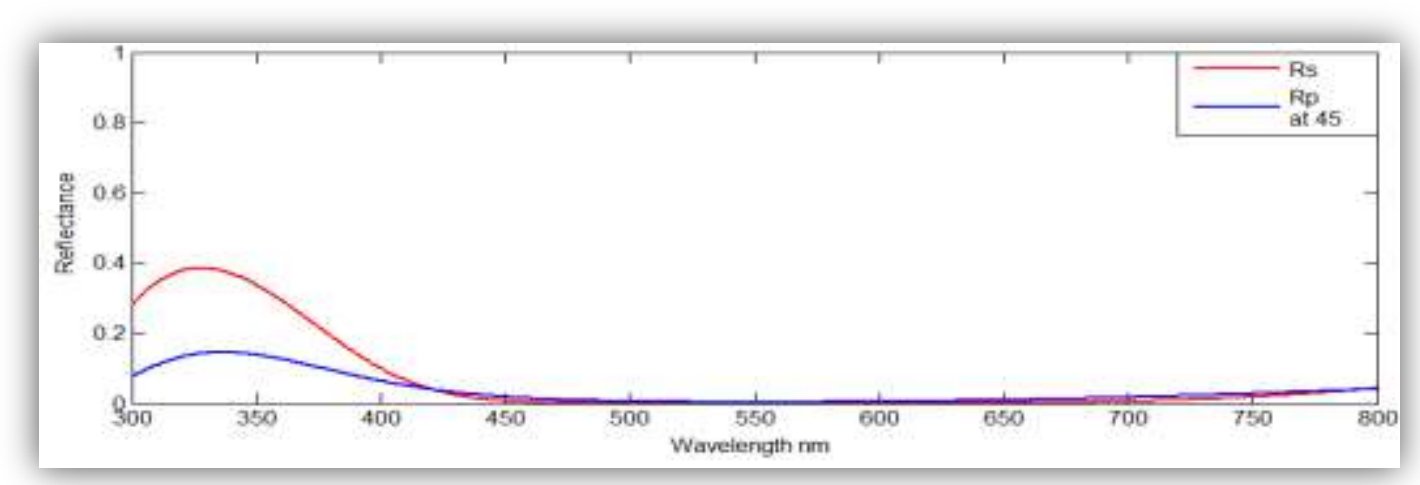

Figure (3.a) optical performance of non polarization ARC, $\theta_{\mathrm{o}}=45^{\circ}$ with construction design stack :Air $\mid 1.1645$ $\mathrm{L}|1.0486(2 \mathrm{H})| 1.0996 \mathrm{M} \mid$ Glass 
At $\theta_{\mathrm{o}}=50^{\circ}, 55^{\circ}$ we carried out new construction design stacks of non-polarized broadband antireflection with proper performance where we obtained The same optical performance for both $\mathrm{S}$ and P-polarized waves along range of wavelength with low reflection as is shown in figures (3.b, 3.c) . such designs represent a significant progress in the design of non-polarized broadband antireflection at high angles of incidence when we could to overcome the problem of splittingwith keeping get high reducing reflection of glass surface.

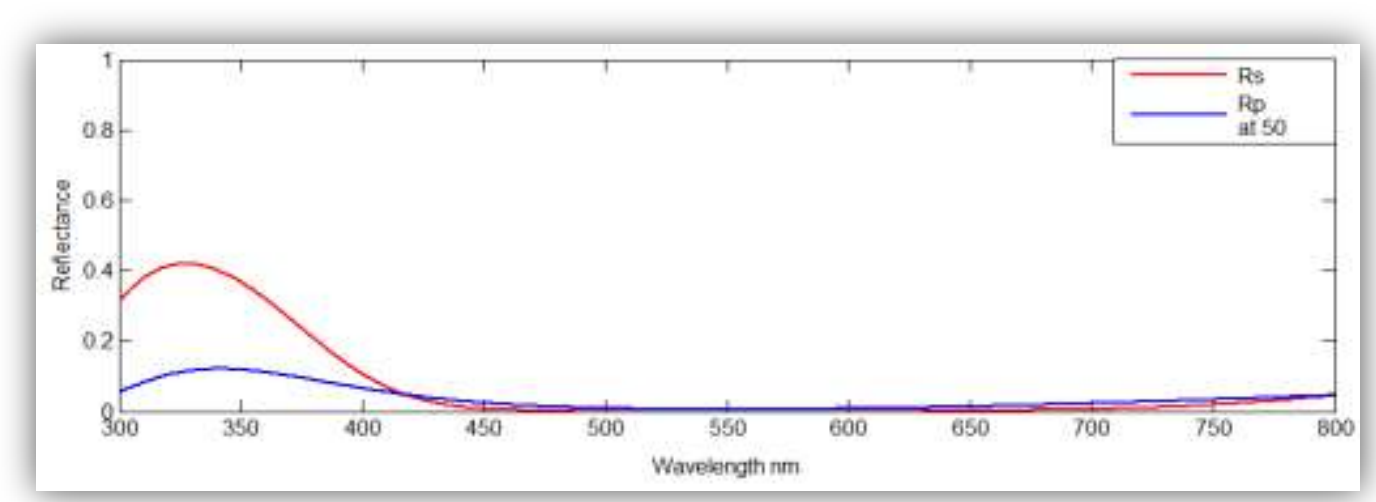

Figure (3.b) optical performance of non polarization ARC, $\theta_{\mathrm{o}}=50^{\circ}$ with construction design stack : Air $\mid 1.2022$ L | $1.0578(2 \mathrm{H})|1.1202 \mathrm{M}|$ Glass

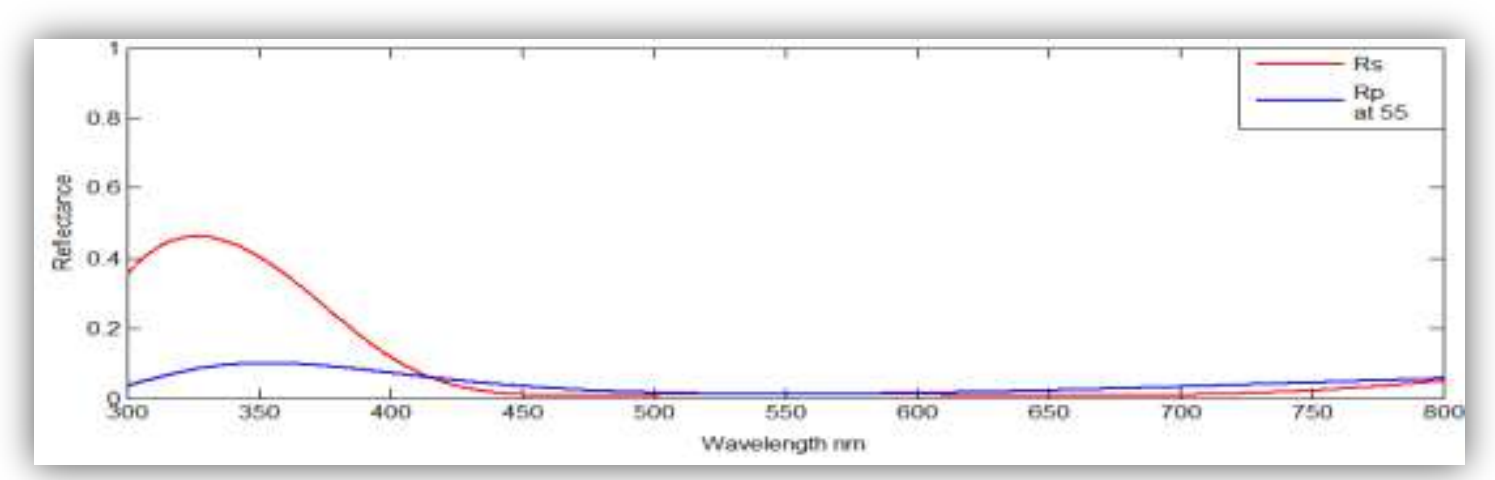

Figure (3.c) optical performance of non polarization ARC, $\theta_{\mathrm{o}}=55^{\circ}$ with construction design stack : Air $\mid 1.2426$ L | $1.0669(2 \mathrm{H}) \mid 1.1412 \mathrm{M}$ |Glass

With professional way in design we achieved another design of non-polarized broadband antireflection at higher angle of incidence $\theta_{\mathrm{o}}=60^{\circ}$. the performance of such design demonstrates good form of Broadband coating despite the high incidence angle such as the low reflection along proper range of wavelengths for both $S$ and P-polarized waves as is shown in figure (3.d) .

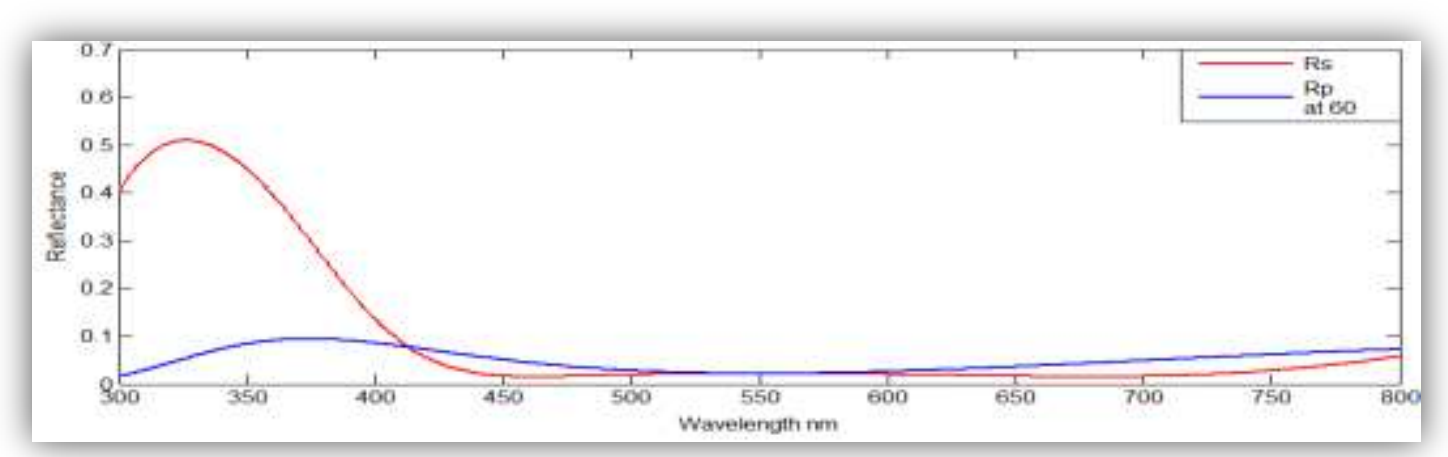

Figure (3.d) optical performance ofnon polarizationARC, $\theta_{\mathrm{o}}=60^{\circ}$ with construction design stack: Air $|1.2844 \mathrm{~L}|$ $1.0757(2 \mathrm{H}) \mid 1.1621 \mathrm{M}$ |Glass 


\section{Conclusion}

This study has presented new construction design stacks of nonpolarizing anti-reflection coatings for visible region (300-800 $\mathrm{nm}$ ). Also preparing and modeling promising coating materials system for use in design of non-polarizing antireflection coatings at high incident angles. Successfully we got optimal optical performance of non-polarizing for the three types of anti reflection coatings. Results refer that overcome the problem of splitting the optical performance into $\mathrm{S}$ and $\mathrm{P}$-mode and reducing or eliminating the separation between them with increasing incident angle. Also we accomplished designs that provide low reflection where we reached to limit the effect of increase of incidence angles.

\section{References}

[1]. Jinn-Moon Yang and Cheng-Yan Kao, (2001),"Efficient evolutionary algorithm for the thin-film synthesis of inhomogeneous optical coatings", Appl.Op,vol. 40, no. $19,3256-3267$.

[2]. J.M. Yang and C-Y. Kao, (2000), "A robust evolutionary algorithm for optical thin-film designs", Proceedings of the 2000 Congress on Evolutionary Computation, La Jolla , California, USA., pp. 978-985.

[3]. Alaa N.Abed AL-Gaffar, Haifa G.Rashid, Ansam Q.Gahdban, "Modelling and optimum design band pass filter for mid IR region", Journal of Baghdad for Science Vol .11, no.3, (2014) .

[4]. Alaa Nazar Abd algaffar, Alyaa Hussein Ali, Narmeen Ali Jasem, "New Construction Stacks for Optimization Designs of Edge Filter", IOSR Journal of Applied Physics (IOSR-JAP, Vol. 8, Issue 3 Ver. II (May. - Jun. 2016), PP 20-26.

[5]. M. A. Kats, J. Byrnes, R. Blanchard, M. Kolle, P. Genevet, (2013), "Enhancement of absorption and color contrast in ultra-thin highly absorbing optical coatings", Appl. Phys. Lett. Vol.103, pp.101-104.

[6]. A. Thelen, (1989), Design of optical interference coatings, McGraw-Hill.

[7]. Alaa Nazar abudalghaffar, Narmeen Ali Jasem,"Study design edge filter using synthesis needle technique", IJSER, Vol. 6, Issue 5, May-2015.

[8]. H. A. Macleod, (2010), Thin-film optical filters, $4^{\text {th }}$ edtion, CRC press Taylor and Francis group.

[9]. M.H. Asghar, M.B. Khan, and S. Naseem, (2003)," Modeling high performance multilayer antireflection coatings for visible and infrared(3.5mm) substrates", Semiconductor Physics, Quantum Electronics \& Optoelectronics. vol. 6, no. 4, pp. 508-513.

[10]. Ozlem Duyar, Huseyin Zafer, " Design and Preparation of Antireflection and Reflection Optical Coatings" Turk J Phys, Vol.28, pp.139-144, (2004).

[11]. R.R. Willey, (2005), "Non-Polarizing Beamsplitter and AR Coating Design ", Society of Vacuum Coaters, ISSN 0737-5921

[12]. AlaaNazar," Open Filters: For optimum design wideband ARC's atoblique incidence of light and effect dispersion of material coating", journal of education college, Al Mustansiryiah University, Vol.2,No.1, (2011).

[13]. H. M. Liddell, "Computer aided techniques for the design of multi-layer filters", Adam Hilger Ltd, ISBN 0-85274-233-9, 2, (1981)

[14]. H. A. Macleod, (2007), Optical thin films, Thin film center Inc. 